Open Access

\title{
Influence of type 2 diabetes on local production of inflammatory molecules in adults with and without chronic periodontitis: a cross-sectional study
}

Hasaan G. Mohamed ${ }^{1,2^{*}}$, Shaza B. Idris ${ }^{1}$, Mutaz F. Ahmed ${ }^{3}$, Anne N. Åstrøm ${ }^{1}$, Kamal Mustafa', Salah O. Ibrahim ${ }^{1}$ and Manal Mustafa ${ }^{4}$

\begin{abstract}
Background: Pathological changes in periodontal tissues are mediated by the interaction between microorganisms and the host immune-inflammatory response. Hyperglycemia may interfere with this process. The aim of this study was to compare the levels of 27 inflammatory molecules in the gingival crevicular fluid (GCF) of patients with type 2 diabetes, with and without chronic periodontitis, and of chronic periodontitis subjects without diabetes. A putative correlation between glycated haemoglobin $(\mathrm{HbA1c})$ and levels of the inflammatory molecules was also investigated.

Methods: The study population comprised a total of 108 individuals, stratified into: 54 with type 2 diabetes and chronic periodontitis (DM + CP), 30 with chronic periodontitis (CP) and 24 with type 2 diabetes (DM). Participants were interviewed with the aid of structured questionnaire. Periodontal parameters (dental plaque, bleeding on probing and periodontal pocket depth) were recorded. The GCF levels of the 27 inflammatory molecules were measured using multiplex micro-bead immunoassay. A glycated haemoglobin (HbA1c) test was performed for patients with diabetes by boronate affinity chromatography.
\end{abstract}

Results: After adjustment for potential confounders, the DM + CP group had higher levels of IL-8 and MIP-1 $\beta$, and lower levels of TNF- $a$, IL-4, INF- $\gamma$, RANTES and IL-7 compared to the CP group. Moreover, the DM + CP group had lower levels of IL-6, IL-7 and G-CSF compared to the DM group. The DM group had higher levels of IL-10, VEGF, and G-CSF compared to the CP group. The levels of MIP-1a and FGF were lower in diabetes patients (regardless of their periodontal status) than in chronic periodontitis subjects without diabetes. Diabetes patients (DM + CP and DM) had higher Th-2/Th-1 ratio compared to the CP group. HbA1c correlated positively with the pro-inflammatory cytokines (Pearson correlation coefficient $=0.27$, $P$ value: 0.02 ).

Conclusion: Type 2 diabetes and chronic periodontitis may influence the GCF levels of inflammatory molecules synergistically as well as independently. Type 2 diabetes was associated with high Th-2/Th-1 ratio, and modulated the local expression of molecules involved in the anti-inflammatory and healing processes.

Keywords: Diabetes mellitus, Chronic periodontitis, Inflammation, Gingival crevicular fluid, Cytokines

\footnotetext{
*Correspondence: hasaanmiligy@hotmail.com

'Department of Clinical Dentistry, Faculty of Medicine and Dentistry,

University of Bergen, Årstadveien 19, 5009 Bergen, Norway

${ }^{2}$ Department of Oral Rehabilitation, Faculty of Dentistry, University of

Khartoum, Khartoum, Sudan

Full list of author information is available at the end of the article
}

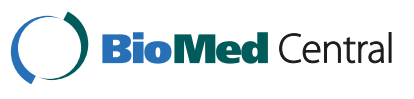

(C) 2015 Mohamed et al. This is an Open Access article distributed under the terms of the Creative Commons Attribution License (http://creativecommons.org/licenses/by/4.0), which permits unrestricted use, distribution, and reproduction in any medium, provided the original work is properly credited. The Creative Commons Public Domain Dedication waiver (http:// creativecommons.org/publicdomain/zero/1.0/) applies to the data made available in this article, unless otherwise stated. 


\section{Background}

Diabetes mellitus represents a heterogeneous group of metabolic disorders in which elevated blood glucose levels result in disturbance of carbohydrate, fat and protein metabolism [1]. The most common form is type 2 diabetes [2]. Diabetes is a major public health concern with 380 million people suffering from the disease worldwide, and about $80 \%$ of the patients are from lowand middle-income countries [3]. It is expected that Africa will take the lead in terms of the largest proportional increase in adults with diabetes by 2030 [4]. Prevalence of diabetes in The Sudan, as in many other low-income countries, is increasing to epidemic proportions [5]. In 2014, the prevalence of the disease in The Sudan was about $18 \%$ [3], which ranks The Sudan among countries with high prevalence of diabetes in Africa and the world. It also reflects the change in life style and the urbanization movement of the population.

Chronic hyperglycemia is associated with irreversible complications such as nephropathy, retinopathy, neuropathy, cardiovascular diseases, peripheral vascular diseases, delayed healing and periodontal diseases [6]. Periodontal diseases, including the reversible form (gingivitis), are highly prevalent and affect up to $90 \%$ of adults worldwide [7]. Chronic periodontitis is characterized by apical migration of the epithelial attachment accompanied by loss of connective tissue and alveolar bone [8]. These changes are mediated by the interaction between pathogens and the host immune-inflammatory response [9]. Although periodontal pathogens are considered as the initiative factor of the disease, [10] tissue destruction in chronic periodontitis is the consequence of the host response to those pathogens [11].

The exact mechanism by which diabetes affects periodontal tissues is not fully elucidated [12]. An altered immune-inflammatory response to bacterial pathogens has been suggested [11]. Hyperglycemia can affect periodontal tissues by increasing oxidative stress as a result of the imbalance between reactive oxygen species and antioxidants, which may eventually lead to accumulation of Advanced Glycation End products (AGE) [13]. The binding of AGE to their receptors (RAGE) triggers intracellular events that enhance the production of proinflammatory cytokines, chemokines and cell adhesion molecules [14]. Hyperglycemia can be assessed by measuring the concentration of glycated haemoglobin (HbA1c), which reflects mean glucose levels over the previous $8-12$ weeks [15].

One means of investigating the local inflammatory status of the oral cavity is by analysis of gingival crevicular fluid (GCF), a non-invasive approach for assessing the presence or absence of various inflammatory molecules [16]. GCF is a transudate or an inflammatory exudate that can be collected from the gingival crevice surrounding the teeth. It contains components of circulating blood, local tissues and most importantly, host-derived inflammatory molecules [16, 17].

Most of the studies of GCF inflammatory molecules in individuals with diabetes have generally been based on small subject samples and investigation of a limited number of inflammatory molecules, with inconclusive results [12]. Multiplex analysis of inflammatory molecules, whereby a large number of inflammatory molecules can be investigated at the same time, would facilitate understanding of the inflammatory process involved in both diabetes and periodontal diseases.

The aim of this study was to investigate the effect of type 2 diabetes on the local expression of inflammatory molecules involved in periodontal inflammation and healing by comparing GCF levels of 27 inflammatory molecules in patients with type 2 diabetes, with and without chronic periodontitis, and in chronic periodontitis subjects without diabetes. A putative correlation between $\mathrm{HbA} 1 \mathrm{c}$ and the molecules under investigation was also explored. We tested the hypothesis that type 2 diabetes adversely influences the local expression of the inflammatory molecules under investigation.

\section{Methods}

\section{Study design and participants}

In all, 108 individuals were enrolled in the study, representing a randomly selected subset from 461 participants recruited for a previous study by Mohamed et al. [18]. The subjects were stratified into three groups: 54 with type 2 diabetes and chronic periodontitis $(\mathrm{DM}+\mathrm{CP}), 30$ with chronic periodontitis $(\mathrm{CP})$ and 24 with type 2 diabetes (DM). The study participants were aged 24-70 years. Diabetes patients were recruited from The Jaber Abol'ez Diabetes Center in Khartoum-Sudan. Diabetes was diagnosed by specialist physicians at the center according to the criteria of The American Diabetes Association [19]. Whole blood samples obtained from patients with diabetes were analysed for $\mathrm{HbA1c}$ by boronate affinity chromatography using a commercially available kit (LabonaCheck ${ }^{\mathrm{m}}$ A1c analyzer) [20]. The CP group was recruited from the out-patient dental clinic at the Khartoum Dental Teaching Hospital. Recruitment of study participants and eligibility criteria for enrolment have been described earlier [18]. Briefly, criteria for enrolment were (i), being diagnosed with type 2 diabetes for more than one year and attending a specialized diabetes clinic -for patients with diabetes- (ii), having at least 10 remaining teeth (iii), no antibiotic, no steroidal and/or non-steroidal anti-inflammatory medication used during the last 3 weeks (iv), not treated with immunosuppressive chemotherapy, no current acute illness, no professional periodontal treatment received during the last 6 months and no ongoing pregnancy or lactation. 
Demographic data were obtained from the study participants by means of a structured questionnaire.

The study protocol was approved by The Ministry of Health in The Sudan and The Norwegian Research Ethics Committee at The University of Bergen (2012/1470/REK Vest). The study participants were enrolled between July and December 2012. Written informed consent was obtained from each participant after the project objectives, the steps in the oral clinical examination and the sampling procedures had been explained. The participants were informed of their dental diagnosis and referred for appropriate dental treatment if indicated.

\section{Clinical periodontal examination}

All clinical assessments, group allocations and samplingsite selection were undertaken by a single, calibrated examiner (HGM). The periodontal examination included all teeth except the $3^{\text {rd }}$ molars using a color-coded periodontal probe (N22, 2-4-6-8-10-12 mm markings), a color-coded Nabors furcation probe (NAB2, 3-6-9-12 $\mathrm{mm}$ markings), curette, mirror, probe, tweezers and cotton rolls. The clinical examination comprised dental plaque assessment using the Silness and Loe Index [21], bleeding on probing (BoP), scored as present or absent, and probing depth (measured from the gingival margin to the base of the periodontal pocket in millimeters) at four sites on each tooth (mesial, distal, buccal and lingual). Participants were diagnosed as having chronic periodontitis if they had at least two sites with bleeding pockets of $\geq 4 \mathrm{~mm}$ (not on the same tooth) $[22,23]$. The oral examination was repeated for 20 participants randomly selected within 2 weeks. Intra-examiner reliability was assessed by Cohen's kappa coefficient [24]. Kappa value (К) was 0.88 for chronic periodontitis (yes/no).

\section{GCF sampling}

GCF samples were collected using perio-paper strips, (PERIOPAPER ${ }^{\circ}$ Gingival Fluid Collection Strips, Oraflow Inc., New York, USA). Four samples, each representing a quadrant, were collected from each participant. The strip was inserted into the mesiobuccal site of the sulcus/pocket of the $1^{\text {st }}$ molar. If missing, the $2^{\text {nd }}$ molar, $2^{\text {nd }}$ premolar or $1^{\text {st }}$ premolar was sampled, respectively. Quadrants with no posterior teeth were excluded from the sampling. After the supra-gingival biofilm had been removed with sterile cotton pellets, the sites were dried and isolated with cotton rolls. The paper strips were inserted $2 \mathrm{~mm}$ into the sulcus/pocket and left in place for $30 \mathrm{~s}$. Strips that were visually assessed as contaminated with blood or saliva were discarded. The 4 strips were immediately pooled in one tube, labeled and stored in liquid nitrogen for further analysis.

\section{Protein extraction and quantification}

For protein extraction, Tween buffer $(230 \mu \mathrm{l})$ was added to each of the tubes containing the 4 strips. The tubes were shaken for $30 \mathrm{~min}$ and then centrifuged for $10 \mathrm{~min}$ at $4{ }^{\circ} \mathrm{C}$ and $1400 \mathrm{rpm}$. The extracted protein was quantified using a commercially available kit and following the manufacturer's instructions (Pierce BCA Protein Assay Kit, Thermo scientific, Rockford, USA). Absorbance was measured at $560 \mathrm{~nm}$ on a plate reader (FLUOstar OPTIMA- BMG Labtech, Germany). Total protein per sample (4 strips) was calculated in micrograms $(\mu \mathrm{g})$.

\section{Analysis and grouping of inflammatory molecules}

Following protein extraction, GCF samples (20 $\mu \mathrm{l}$ each) were processed by multiplex immunoassay containing fluorescent dyed microspheres conjugated with monoclonal antibody specific for 27 inflammatory molecules (Bio-Plex Human Cytokine Assay; Bio-Rad Inc., Hercules, CA, USA) [25]. The following molecules were investigated: $I L-1 \beta, I L-1 r a, I L-2, I L-4, I L-5, I L-6, I L-7, I L-8$, IL-9, IL-10, IL-12, IL-13, IL-15, IL-17, Eotaxin, Basic Fibroblast Growth Factor (FGF), Granulocyte Colony Stimulating Factor (G-CSF), Granulocyte-Monocyte Colony Stimulating Factor (GM-CSF), Interferon- $\gamma$ (INF- $\gamma$ ), Interferon Inducible Protein-10 (IP-10), Monocyte Chemo-attractive Protein-1 (MCP-1), Macrophage Inflammatory Protein-1 $\alpha$ (MIP-1 $\alpha)$, Macrophage Inflammatory Protein-1 $\beta$ (MIP-1 $\beta$ ), Platelet-Derived Growth Factor (PDGF), Regulated Upon Activation, Normally T-Expressed, and Presumably Secreted (RANTES), Tumor Necrosis Factor- $\alpha$ (TNF- $\alpha$ ) and Vascular Endothelial Growth Factor (VEGF). Samples were diluted 1:4 $(50 \mu \mathrm{l}$ in total) and incubated with coupled beads. Complexes were washed, incubated with detection antibody and thereafter, with Streptavidin-Phycoerythrin. A range of $105876-0.29 \mathrm{pg} / \mathrm{ml}$ recombinant cytokines was used to establish the standard curves. The levels of the inflammatory molecules were measured on a multiplex array reader (Bio-Plex Workstation from Bio-Rad Laboratories). The final quantities were calculated using software provided by the manufacturer and were reported as picograms per $30 \mathrm{~s}(\mathrm{pg} / 30 \mathrm{~s})$ [26].

Based on the biological effect of each molecule, the molecules under investigation were grouped as: proinflammatory cytokines (IL-1 $\beta$, IL-6, IL-9, IL-12 and TNF- $\alpha$ ), anti-inflammatory cytokines (IL-4 and IL-10), chemokines (IL-8, IP-10, MCP-1, MIP- $1 \alpha$, MIP- $1 \beta$ and RANTES) and T-helper 2/T-helper 1 ratio (Th-2/Th-1) (IL-4, IL-6, IL-9, IL-10/INF- $\gamma$, IL-2).

\section{Statistical analysis}

Inter-group differences in demographic and clinical data were assessed using chi-square and Fisher's exact test for categorical variables, one way analysis 
of variance (ANOVA) with post-hoc (Sidak) adjustment for multiple comparisons for normally distributed continuous variables, and Kruskal-Wallis and Mann-Whitney test for skewed data. Since the distribution of the levels of the studied molecules is skewed, the natural logarithm links were calculated and used to detect the differences between the study groups, and one way analysis of variance (ANOVA) with post-hoc (Sidak) was conducted. Generalized linear models (GLM) with Gaussian family and log function were used to adjust for the potentially confounding effect of age, gender, smoking status, dental plaque, BoP and total protein on the outcome (molecule quantities). A possible correlation between HbA1c and the inflammatory status was investigated using Pearson correlation. Stata 13 (StataCorp. 2013. Stata Statistical Software: Release 13. College Station, TX: StataCorp LP.) was used for data analysis. P values less than 0.05 were considered statistically significant.

\section{Results}

The demographic characteristics and clinical parameters of the study groups are presented in Table 1. BoP was the only clinical parameter that differed significantly between the groups. It was higher in the $\mathrm{DM}+\mathrm{CP}$ group than in the $\mathrm{CP}$ and $\mathrm{DM}$ groups. The following inflammatory molecules, which were not detected in more than $30 \%$ of the GCF samples, were excluded from the analysis: (IL-1ra, IL-5, IL-13, IL-15 and eotaxin). The unadjusted means of the quantities of the detected molecules across the study groups are presented in Table 2. After adjustment for potential confounders (age, gender, smoking status, BoP, dental plaque index and total protein), the $\mathrm{DM}+\mathrm{CP}$ group had higher levels of IL-8 and MIP$1 \beta$, and lower levels of TNF- $\alpha$, IL-4, INF- $\gamma$, RANTES and IL-7 compared to the $\mathrm{CP}$ group. Moreover, the $\mathrm{DM}+\mathrm{CP}$ group had lower levels of IL-6, IL-7 and G-CSF than the DM group. The DM group had higher levels of IL-10, VEGF, and G-CSF than the $\mathrm{CP}$ group. Both diabetes groups $(\mathrm{DM}+\mathrm{CP}$ and $\mathrm{DM})$ had lower levels of MIP-1 $\alpha$ and FGF compared to chronic periodontitis subjects without diabetes (CP) (Table 3).

The Th-2/Th-1 ratio was significantly higher in the diabetes groups $(\mathrm{DM}+\mathrm{CP}$ and $\mathrm{DM})$ than in the $\mathrm{CP}$ group (Fig. 1d). A weak positive correlation was observed between HbAlc and the levels of the proinflammatory cytokines (Pearson correlation coefficient: 0.27 , P value: 0.02 ) (Fig. 2), while the correlation between $\mathrm{HbA1c}$ and the anti-inflammatory cytokines was not statistically significant (Pearson correlation coefficient: -0.11 , P value: 0.33 ) (Fig. 3).
Table 1 Distribution of socio-demographic and clinical indicators by study groups

\begin{tabular}{|c|c|c|c|}
\hline Variable & $\mathrm{DM}+\mathrm{CP}(n=54)$ & $\mathrm{CP}(n=30)$ & $\mathrm{DM}(n=24)$ \\
\hline$\overline{\text { Age, mean }(\mathrm{SE})^{1}}$ & $54.76(1.37)$ & $55.37(1.83)$ & $50.79(2.05)$ \\
\hline \multicolumn{4}{|l|}{ Gender, $\%(n)^{2}$} \\
\hline Male & $42.59(23)$ & $60.00(18)$ & $29.17(7)$ \\
\hline Female & $57.41(31)$ & $40.00(12)$ & $70.83(17)$ \\
\hline \multicolumn{4}{|l|}{ Education, $\%(n)^{2}$} \\
\hline Illiterate & $29.63(16)$ & $33.33(10)$ & $20.83(5)$ \\
\hline Literate & 70.37 (38) & $66.67(20)$ & $79.17(19)$ \\
\hline \multicolumn{4}{|l|}{ Employment, \% (n) ${ }^{2}$} \\
\hline Unemployed & $62.96(34)$ & $43.33(13)$ & $70.83(17)$ \\
\hline Employed & $37.04(20)$ & $56.67(17)$ & $29.17(7)$ \\
\hline \multicolumn{4}{|l|}{ Smoking, \% (n) ${ }^{3}$} \\
\hline Yes & $12.96(7)$ & $26.67(8)$ & $12.50(3)$ \\
\hline No & $87.04(47)$ & $73.33(22)$ & $87.50(21)$ \\
\hline \multicolumn{4}{|l|}{ Hypertension, \% (n) ${ }^{2}$} \\
\hline Yes & $31.48(17)$ & $20.00(6)$ & $29.17(7)$ \\
\hline No & $68.52(37)$ & $80.00(24)$ & $70.83(17)$ \\
\hline \multicolumn{4}{|l|}{$\begin{array}{l}\text { Regular dental } \\
\text { attendance, \% (n) }\end{array}$} \\
\hline Yes & $3.70(2)$ & $10.00(3)$ & $8.33(2)$ \\
\hline No & $96.30(52)$ & $90.00(27)$ & $91.67(22)$ \\
\hline $\begin{array}{l}\text { Duration of diabetes, } \\
\text { mean }(\mathrm{SE})^{4}\end{array}$ & $8.44(0.83)$ & -—- & $9.67(1.70)$ \\
\hline $\mathrm{HbA1c} \%$, mean $(\mathrm{SE})^{5}$ & $9.17(0.24)$ & - - & $9.25(0.49)$ \\
\hline $\begin{array}{l}\text { Plaque index, mean } \\
(\mathrm{SE})^{1}\end{array}$ & $1.66(0.05)$ & $1.40(0.06)$ & $1.47(0.07)$ \\
\hline
\end{tabular}

Percentage of teeth with BoP, mean (SE)

$28.97(3.82) b^{* *} 32.51(4.28) b^{* *}$

Pocket depth, \% (n)

$\begin{array}{llll}4-5 \mathrm{~mm} & 59.30(32) & 70.00(21) & 0.00(0) \\ \geq 6 \mathrm{~mm} & 40.70(22) & 30.00(9) & 0.00(0) \\ \text { Pocket depth, mean } & 4.16(0.09) & 4.25(0.12) & - \\ \text { (SE) }^{4} & & & \\ \begin{array}{l}\text { Total protein - } \mathrm{Lg}, \\ \text { mean (SE) }\end{array} & 82.78(7.53) & 84.23(15.25) & 77.84(9.06)\end{array}$

Different letters indicate statistically significant differences

'one-way ANOVA

${ }^{2}$ chi-square test

${ }^{3}$ Fisher's exact test

${ }^{4}$ Mann-Whitney $U$ test

${ }^{5}$ Independent sample $T$ test

${ }^{6}$ Kruskal-Wallis test

**P $P<0.01$

\section{Discussion}

Pro-inflammatory cytokines induce inflammatory response to various stimuli such as bacterial lipopolysaccharides [27]. In patients with diabetes, IL-1 $\beta$ is regarded as one of the key cytokines in inflammatory periodontal tissue destruction [28]. In the present study, the level of IL-1 $\beta$ was highest in the $\mathrm{DM}+\mathrm{CP}$ group, 
Table 2 Levels of the detected inflammatory molecules among the study groups (pg/30s)

\begin{tabular}{|c|c|c|c|}
\hline $\begin{array}{l}\text { Inflammatory } \\
\text { molecule, mean (SE) }\end{array}$ & $\mathrm{DM}+\mathrm{CP}(n=54)$ & $\mathrm{CP}(n=30)$ & $\mathrm{DM}(n=24)$ \\
\hline IL-1 $\beta$ & 350.50 (31.18) & $260.31(41.45)$ & $261.74(46.34)$ \\
\hline IL-6 & $9.01(0.83) a$ & 11.12 (1.11)ab & $12.67(1.27) b^{*}$ \\
\hline IL-9 & $6.91(0.57)$ & $9.64(0.76)$ & $8.57(0.87)$ \\
\hline IL-12 & $13.93(1.07)$ & $16.44(1.43)$ & $17.13(1.63)$ \\
\hline TNF-a & $17.70(1.84) \mathrm{a}$ & $31.57(2.47) b^{* *}$ & 22.05 (2.82)ab \\
\hline $\mid \mathrm{L}-4$ & $0.83(0.06) a$ & $1.26(0.09) b^{* *}$ & 0.92 (0.10)ab \\
\hline IL-10 & 27.74 (1.43)ab & 23.68 (1.90)a & $33.02(2.17) b^{* *}$ \\
\hline IL-2 & $8.01(0.98) a^{*}$ & $8.93(1.30) a^{*}$ & $12.68(1.48) \mathrm{b}$ \\
\hline INF- $\gamma$ & $29.55(2.61) a^{* *}$ & $47.50(3.50) b$ & $33.89(3.92) \mathrm{a}^{*}$ \\
\hline IL-8 & $633.87(48.22)$ & $501.96(62.25)$ & $507.65(69.60)$ \\
\hline IP-10 & 19.32 (2.30)a & 24.60 (3.01)ab & $29.13(3.43) b^{*}$ \\
\hline MCP-1 & $6.10(0.87) a$ & $10.73(1.11) b^{* *}$ & 7.88 (1.24)ab \\
\hline MIP-1a & $3.14(0.27) a^{*}$ & $4.52(0.36) b$ & $2.98(0.40) a^{*}$ \\
\hline MIP-1 $\beta$ & $23.53(2.64)$ & $21.37(3.54)$ & $26.03(3.95)$ \\
\hline RANTES & $32.93(2.77)$ & 45.64 (3.72) & $40.12(4.16)$ \\
\hline FGF & $76.91(4.62) a^{* *}$ & $105.16(6.20) b$ & $76.34(6.93) a^{*}$ \\
\hline PDGF & 13.05 (0.93)a & $17.22(1.24) b^{*}$ & 15.45 (1.39)ab \\
\hline VEGF & $212.01(11.75)$ & $188.50(15.77)$ & $222.83(17.63)$ \\
\hline IL-7 & $2.63(0.31) a$ & $4.85(0.42) b^{* *}$ & $4.24(0.47) b^{* *}$ \\
\hline G-CSF & $122.73(12.48) a$ & 131.02 (16.75)ab & $196.73(19.13) b^{* *}$ \\
\hline GM-CSF & $621.28(21.82)$ & $558.27(29.28)$ & $555.30(33.44)$ \\
\hline IL-17 & 72.04 (3.71)a & $246.03(62.90) b^{* *}$ & 79.98 (6.68)ab \\
\hline
\end{tabular}

Different letters indicate statistically significant differences using one-way ANOVA for natural log. links of the amounts of inflammatory molecules ${ }^{*} P<0.05$

**P $<0.01$

albeit not statistically significant. A recent meta-analysis reported that type 2 diabetes patients with chronic periodontitis were found to have significantly higher GCF levels of IL-1 $\beta$ than their systemically healthy counterparts [29]. In contrast, others have failed to confirm an association between levels of IL- $1 \beta$ and diabetes in individuals with periodontal disease [30,31]. These inconsistencies might be attributed to the difference in HbA1c levels and the duration of diabetes. Contradictory results were reported from studies of TNF- $\alpha$ levels in oral fluids among patients with diabetes and chronic periodontitis [12]. In the present study, the levels of both TNF- $\alpha$ and IL-7 were lower in the DM + CP group than in the CP group. In contrast, other studies have reported higher GCF levels of TNF- $\alpha$ and IL-7 in patients with type 2 diabetes than in systemically healthy individuals [29, 32]. In this context, it is of interest to note that the levels of pro-inflammatory cytokines and chemokines in the DM group were comparable with those in the CP group, reflecting a local active inflammatory process in the DM
Table 3 Adjusted means of the levels of inflammatory molecules (pg/30s)

\begin{tabular}{llll}
\hline $\begin{array}{l}\text { Inflammatory } \\
\text { molecule, } \\
\text { mean (SE) }\end{array}$ & $\mathrm{DM}+\mathrm{CP}(n=54)$ & $\mathrm{CP}(n=30)$ & $\mathrm{DM}(n=24)$ \\
\hline IL-6 & $9.01(0.94) \mathrm{a}$ & $11.11(1.30) \mathrm{ab}$ & $14.01(1.50) \mathrm{b}^{*}$ \\
TNF-a & $17.68(2.06) \mathrm{a}$ & $31.64(3.16) \mathrm{b}^{* *}$ & $23.13(3.20) \mathrm{ab}$ \\
IL-4 & $0.84(0.07) \mathrm{a}$ & $1.25(0.11) \mathrm{b}^{*}$ & $0.96(0.11) \mathrm{ab}$ \\
IL-10 & $28.82(1.66) \mathrm{ab}$ & $22.46(1.99) \mathrm{a}$ & $33.72(2.42) \mathrm{b}^{* *}$ \\
INF-y & $30.62(2.99) \mathrm{a}$ & $45.77(4.29) \mathrm{b}^{*}$ & $36.88(4.62) \mathrm{ab}$ \\
IL-8 & $699.48(53.44) \mathrm{a}$ & $464.17(57.03) \mathrm{b}^{*}$ & $503.04(71.04) \mathrm{ab}$ \\
MIP-1a & $3.05(0.32) \mathrm{a}^{*}$ & $4.79(0.47) \mathrm{b}$ & $2.99(0.45) \mathrm{a}^{*}$ \\
MIP-1 $\beta$ & $28.71(3.05) \mathrm{a}$ & $16.84(2.86) \mathrm{b}^{*}$ & $22.37(3.40) \mathrm{ab}$ \\
RANTES & $31.94(3.14) \mathrm{a}$ & $48.01(4.70) \mathrm{b}^{*}$ & $41.16(4.79) \mathrm{ab}$ \\
FGF & $71.66(5.17) \mathrm{a}^{* *}$ & $113.28(7.90) \mathrm{b}$ & $80.86(7.93) \mathrm{a}^{* *}$ \\
VEGF & $215.04(12.69) \mathrm{ab}$ & $177.52(16.40) \mathrm{a}$ & $255.82(19.39) \mathrm{b}^{* *}$ \\
IL-7 & $2.81(0.35) \mathrm{a}$ & $4.47(0.51) \mathrm{b}^{*}$ & $4.78(0.56) \mathrm{b}^{*}$ \\
G-CSF & $131.71(14.41) \mathrm{a}^{*}$ & $116.98(17.79) \mathrm{a}^{* *}$ & $206.60(21.25) \mathrm{b}$ \\
\hline DIfer & &
\end{tabular}

Different letters indicate statistically significant differences using GLM with Gaussian family and log. function adjusting for age, gender, smoking status, BoP, dental plaque index and total protein ${ }^{*} P<0.05$

${ }^{* *} P<0.01$

group (Fig. 1a-1c). A weak positive correlation was observed between HbA1c and the levels of proinflammatory cytokines. Another study reported a significant positive correlation between IL-1 $\beta$ levels in GCF and HbA1c [33].

Studying the effect of IL-6 and IL-10, particularly in cross-sectional studies, is complicated by the fact that both are multifunctional cytokines (i.e. pro- and antiinflammatory) [34, 35]. IL-6 is involved in activation of osteoclasts and Th-17 cells [36]. In contrast, it also induces the production of IL-1ra, thus contributes to the anti-inflammatory process [37]. There is no evidence to support an association between increased levels of IL-6 and destructive periodontal disease among individuals with hyperglycemia [38]. However, Javed et al., [39] reported that up-regulation of IL- 6 together with IL- $1 \alpha$ could be associated with diabetes related periodontal tissue destruction. In the present study, the levels of the anti-inflammatory cytokine IL-4 were lower in the $\mathrm{DM}+\mathrm{CP}$ group than in the CP group. It has been reported that IL-4 is down-regulated in patients with type 2 diabetes [40]. In addition, in an in-vivo animal model for ligament healing, IL-4 was found to contribute to the proliferative phase of healing [41].

Chemokines are small peptides that recruit immune cells from the circulation to the tissues as needed [42]. Most investigations of the role of chemokines have focused on IL-8 [12]. In the present study, IL-8 was upregulated in the $\mathrm{DM}+\mathrm{CP}$ group compared to the $\mathrm{CP}$ 

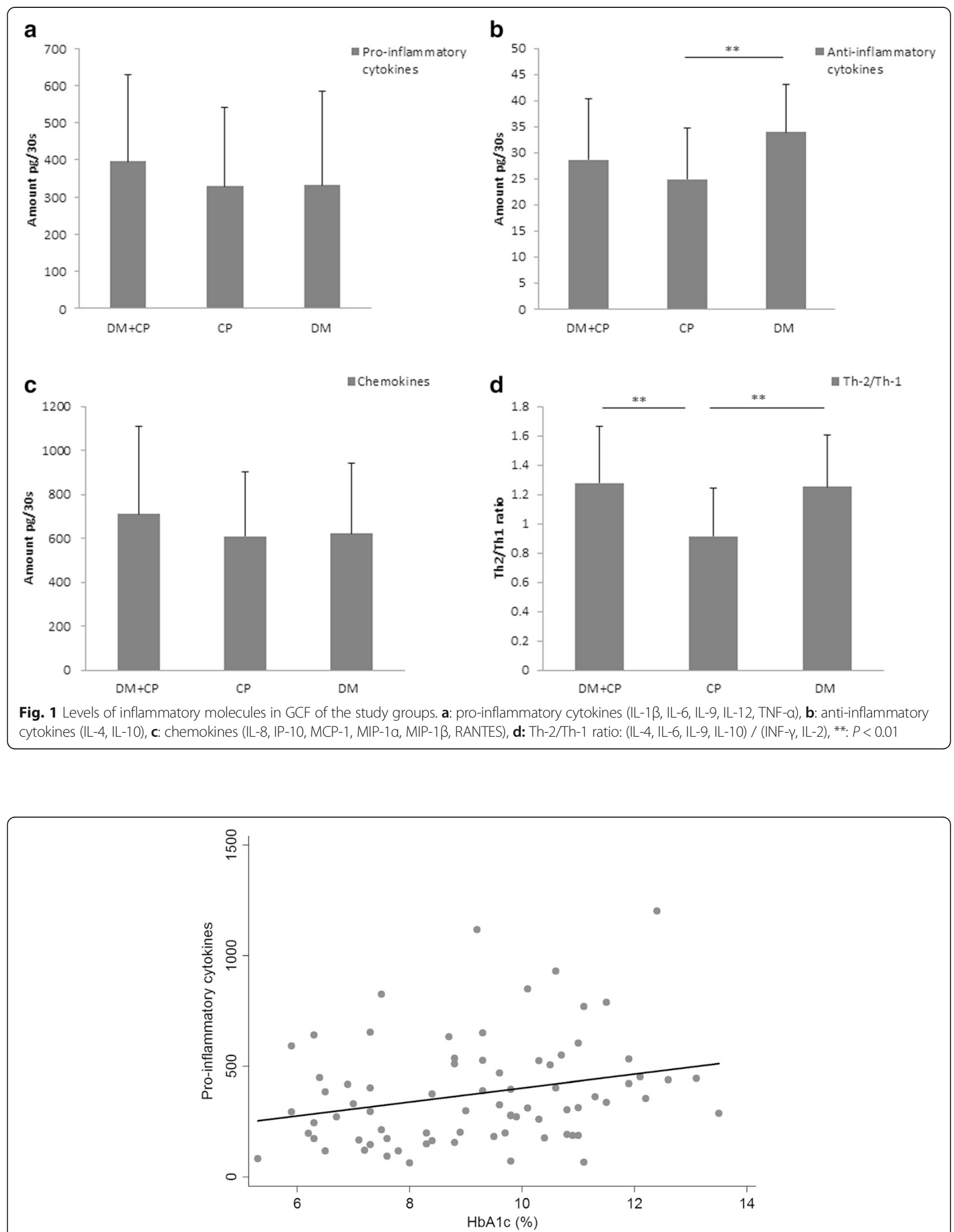

Fig. 2 Correlation between HbA1c and the pro-inflammatory cytokines. Pearson correlation coefficient: 0.27, P value: 0.02 


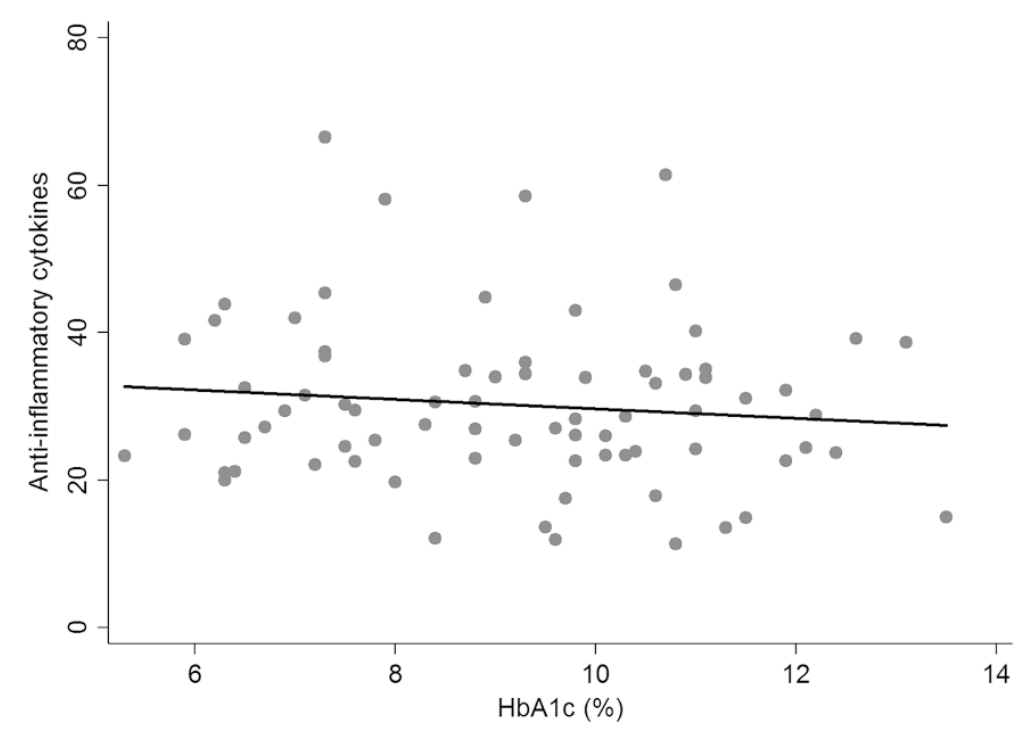

Fig. 3 Correlation between HbA1c and the anti-inflammatory cytokines. Pearson correlation coefficient: -0.11, P value: 0.33

group. The same trend has been observed in an investigation of serum levels of IL-8 [43]. MIP- $1 \alpha$ is a potent chemokine that attracts macrophages, T-cytotoxic and natural killer cells [44]. It was down-regulated in both diabetes groups (DM+CP and $\mathrm{DM})$ compared to the $\mathrm{CP}$ group. In contrast, Duarte et al., [32] reported higher levels of MIP- $1 \alpha$ in patients with poorly controlled type 2 diabetes compared to systemically healthy controls. The present study demonstrated lower levels of RANTES in the DM + CP group compared to the CP group. It was reported that levels of RANTES negatively correlate with increased inflammation [45].

Type 2 diabetes might adversely affect periodontal health by down-regulating molecules involved in periodontal tissue regeneration and healing process such as FGF and PDGF [46, 47]. FGF was detected in lower amounts in the diabetes groups $(\mathrm{DM}+\mathrm{CP}$ and $\mathrm{DM})$ than in the CP group. Moreover, the levels of VEGF were higher in the DM group compared to the CP group. This observation might be explained by the fact that oxidative stress induces the VEGF signaling in patients with type 2 diabetes [48]. Moreover, our VEGF results corroborate with a previous study which reported a non-significant trend towards increased VEGF in GCF of patients with type 2 diabetes and chronic periodontitis compared to systemically healthy individuals with chronic periodontitis [49]. In contrast, Guneri et al., [50] concluded that GCF levels of VEGF were elevated in subjects with chronic periodontitis regardless of their diabetic status.

According to the cytokines they produce, Th-cells are divided into Th-1, Th-2, Th-17 and T-regulatory cells. Th- 1 secretes IL- 2 and INF- $\gamma$, while Th- 2 secretes IL-4,
IL-6, IL-9, IL-10 and IL-13 [51, 52]. Only limited information is available about the role of Th-cells in type 2 diabetes patients with periodontitis [12]. Th-2/Th-1 ratio was higher in both diabetes groups $(\mathrm{DM}+\mathrm{CP}$ and $\mathrm{DM})$ than in the CP group, indicating enhanced humoral response and progression of periodontal disease among patients with type 2 diabetes via Th-2/B-cell axis [53, 54].

In the present study, the low levels of some of the proinflammatory molecules detected in type 2 diabetes patients compared to those without diabetes can be explained by the fact that some of the patients with diabetes were receiving insulin therapy, which might affect the local expression of inflammatory molecules [43, 55]. Moreover, the more pronounced clinical signs of periodontal disease in individuals with type 2 diabetes can be attributed to the disturbance in the balance between the molecules involved in active inflammatory process on the one hand, and the molecules involved in controlling inflammation, healing and regeneration of periodontal tissues on the other hand [56, 57]. Up to date, there is no ideal biomarker that can be nominated for disease detection or progression. Therefore, the interest has been shifted towards considering combinations of various host responses $[11,58]$. In the present study, the GCF volume was not measured. Therefore, total GCF protein was used as a surrogate measure of the GCF volume in the multivariate analysis to control for the potential effect of variability of GCF volume on our results [59]. In addition, pocket depth and bleeding on probing were both used to define cases with periodontitis, as clinical attachment loss data were not available. Consequently, the effect of type 2 diabetes on the study outcome might be underestimated [60]. Nevertheless, it was reported that both periodontal pocket depth and 
BoP reflect the current disease status and are strongly related to the local inflammatory activity compared to clinical attachment loss, which reflects past disease experience [61-63].

\section{Conclusions}

Type 2 diabetes and chronic periodontitis may adversely influence the GCF levels of inflammatory molecules synergistically as well as independently. Moreover, type 2 diabetes was associated with high Th-2/Th-1 ratio, and adversely influenced the local expression of molecules involved in the anti-inflammatory and healing processes. Further prospective studies are warranted to produce sufficient evidence to support the application of specific GCF biomarkers for prediction and prognosis of periodontal disease among patients with diabetes.

\section{Abbreviations}

GCF: Gingival crevicular fluid; HbA1c: Glycated haemoglobin; AGE: Advanced glycation end products; BoP: Bleeding on probing; IL: Interleukin; FGF: Basic fibroblast growth factor; G-CSF: Granulocyte colony stimulating factor; GM-CSF: Granulocyte-monocyte colony stimulating factor; INF- $\gamma$ : Interferon- $\gamma$; IP-10: Interferon inducible protein-10; MCP-1: Monocyte chemo-attractive protein-1; MIP: Macrophage inflammatory protein; PDGF: Platelet-derived growth factor; RANTES: Regulated upon activation, normally T-expressed, and presumably secreted; TNF-a: Tumor necrosis factor-a; VEGF: Vascular endothelial growth factor; Th: T-helper; ANOVA: Analysis of variance; GLM: Generalized linear model.

\section{Competing interests}

The authors declare that they have no competing interests.

\section{Authors' contributions}

This study was designed by HGM, MFA, ANÅ and SOI. KM Contributed to the materials and analysis tools and to the discussion. HGM performed the laboratory experiments under the supervision of MM and SBI. HGM and ANA analysed the data. HGM wrote the manuscript which was edited by SOI, MM, ANÅ, KM, SBI and MFA. All authors read and approved the final manuscript.

\section{Acknowledgements}

This study was funded by The Norwegian State Educational Loan Fund and the authors declare no conflict of interest. We acknowledge with appreciation the support of Dr. Alrashid Abdulla and the staff at Jaber Abol'ez Diabetes Center, Professor Mohamed Ali Eltoum, the staff of Faculty of Dentistry- University of Khartoum, Khartoum Dental Teaching Hospital and The Department of Clinical Dentistry- University of Bergen. Associate Professor Stein Atle Lie of The Department of Clinical Dentistry, University of Bergen is acknowledged for his contribution to the statistical analysis of the data and Dr. Joan Bevenius-Carrick for editing the manuscript. We also acknowledge the important contribution of the dental assistants who helped in data collection and made this work possible.

\section{Author details}

'Department of Clinical Dentistry, Faculty of Medicine and Dentistry, University of Bergen, Årstadveien 19, 5009 Bergen, Norway. ${ }^{2}$ Department of Oral Rehabilitation, Faculty of Dentistry, University of Khartoum, Khartoum, Sudan. ${ }^{3}$ Hamad Medical Corporation, Doha, Qatar. ${ }^{4}$ Oral Health Competence Center in Western Norway, Hordaland, Bergen, Norway.

Received: 31 March 2015 Accepted: 16 July 2015

Published online: 27 July 2015

\section{References}

1. Alberti KG, Zimmet PZ. Definition, diagnosis and classification of diabetes mellitus and its complications. Part 1: diagnosis and classification of diabetes mellitus provisional report of a WHO consultation. Diabet Med. 1998;15(7):539-53.

2. American Diabetes Association. Diagnosis and classification of diabetes mellitus. Diabetes Care 2014, 37 Suppl 1:S81-90.

3. International Diabetes Federation. IDF Diabetes Atlas update poster, 6th edn. Brussels, Belgium. International Diabetes Federation 2014.

4. Shaw JE, Sicree RA, Zimmet PZ. Global estimates of the prevalence of diabetes for 2010 and 2030. Diabetes Res Clin Pract. 2010;87:4-14.

5. Abdelgadir M, Elbagir M, Eltom M, Berne C. The influence of glucose self-monitoring on glycaemic control in patients with diabetes mellitus in Sudan. Diabetes Res Clin Pract. 2006;74(1):90-4.

6. Sima C, Glogauer M. Diabetes mellitus and periodontal diseases. Curr Diab Rep. 2013;13(3):445-52

7. Pihlstrom BL, Michalowicz BS, Johnson NW. Periodontal diseases. Lancet. 2005;366(9499):1809-20.

8. Armitage GC. Periodontal diagnoses and classification of periodontal diseases. Periodontol 2000. 2004;34:9-21.

9. Preshaw PM, Taylor JJ. How has research into cytokine interactions and their role in driving immune responses impacted our understanding of periodontitis? J Clin Periodontol. 2011;38 Suppl $11: 60-84$

10. Kornman KS. Mapping the pathogenesis of periodontitis: a new look. J Periodontol. 2008;79(8 Suppl):1560-8.

11. Hanes PJ, Krishna R. Characteristics of inflammation common to both diabetes and periodontitis: are predictive diagnosis and targeted preventive measures possible? The EPMA journal. 2010;1(1):101-16.

12. Taylor JJ, Preshaw PM, Lalla E. A review of the evidence for pathogenic mechanisms that may link periodontitis and diabetes. J Periodontol. 2013;84(4 Suppl):S113-134.

13. King GL. The role of inflammatory cytokines in diabetes and its complications. J Periodontol. 2008;79(8 Suppl):1527-34

14. Abbass MM, Korany NS, Salama AH, Dmytryk JJ, Safiejko-Mroczka B. The relationship between receptor for advanced glycation end products expression and the severity of periodontal disease in the gingiva of diabetic and non diabetic periodontitis patients. Arch Oral Biol. 2012;57(10):1342-54.

15. Nathan D, Turgeon $\mathrm{H}$, Regan S. Relationship between glycated haemoglobin levels and mean glucose levels over time. Diabetologia. 2007;50(11):2239-44.

16. Lamster IB, Ahlo JK. Analysis of gingival crevicular fluid as applied to the diagnosis of oral and systemic diseases. Ann N Y Acad Sci. 2007;1098:216-29.

17. Griffiths GS. Formation, collection and significance of gingival crevice fluid. Periodontol 2000. 2003:31:32-42.

18. Mohamed HG, Idris SB, Ahmed MF, Bøe OE, Mustafa K, Ibrahim SO, et al. Association between Oral Health Status and Type 2 Diabetes Mellitus among Sudanese Adults: A Matched Case-Control Study. PloS one 2013;8(12):e82158.

19. ADA. Diagnosis and classification of diabetes mellitus. Diabetes Care. 2008;31 Suppl 1:S55-60.

20. Little RR, Roberts WL. A review of variant hemoglobins interfering with hemoglobin A1c measurement. J Diabetes Sci Technol. 2009;3(3):446-51.

21. Silness J, Loe H. Periodontal disease in pregnancy. II. Correlation between oral hygiene and periodontal condition. Acta odontologica Scandinavica. 1964;22:121-35

22. Katagiri $S$, Nagasawa $T$, Kobayashi $H$, Takamatsu $H$, Bharti $P$, Izumiyama $H$, et al. Improvement of glycemic control after periodontal treatment by resolving gingival inflammation in type 2 diabetic patients with periodontal disease. J Diabetes Invest. 2012;3(4):402-9.

23. Eke PI, Page RC, Wei L, Thornton-Evans G, Genco RJ. Update of the case definitions for population-based surveillance of periodontitis. J Periodontol. 2012;83(12):1449-54

24. Cohen J. A coefficient of agreement for nominal scales. Educ Psychol Meas. 1960;20:37-46

25. Houser B. Bio-Rad's Bio-Plex(R) suspension array system, XMAP technology overview. Arch Physiol Biochem. 2012;118(4):192-6.

26. Thunell DH, Tymkiw KD, Johnson GK, Joly S, Burnell KK, Cavanaugh JE, et al. A multiplex immunoassay demonstrates reductions in gingival crevicular fluid cytokines following initial periodontal therapy. J Periodontal Res. 2010;45(1):148-52.

27. Dinarello CA. Proinflammatory cytokines. Chest. 2000;118(2):503-8.

28. Duarte PM, de Oliveira MC, Tambeli CH, Parada CA, Casati MZ, Nociti FHJr. Overexpression of interleukin-1beta and interleukin-6 may play an 
important role in periodontal breakdown in type 2 diabetic patients. J Periodontal Res. 2007:42(4):377-81.

29. Atieh MA, Faggion CMJr, Seymour GJ. Cytokines in patients with type 2 diabetes and chronic periodontitis: A systematic review and meta-analysis. Diabetes Res Clin Pract. 2014;104(2):e38-45.

30. Correa FO, Goncalves D, Figueredo CM, Gustafsson A, Orrico SR. The short-term effectiveness of non-surgical treatment in reducing levels of interleukin-1 beta and proteases in gingival crevicular fluid from patients with type 2 diabetes mellitus and chronic periodontitis. J Periodontol. 2008;79(11):2143-50.

31. Navarro-Sanchez AB, Faria-Almeida R, Bascones-Martinez A. Effect of non-surgical periodontal therapy on clinical and immunological response and glycaemic control in type 2 diabetic patients with moderate periodontitis. J Clin Periodontol. 2007;34(10):835-43.

32. Duarte PM, Bezerra JP, Miranda TS, Feres M, Chambrone L, Shaddox LM. Local levels of inflammatory mediators in uncontrolled type 2 diabetic subjects with chronic periodontitis. J Clin Periodontol. 2014;41(1):11-8.

33. Engebretson SP, Hey-Hadavi J, Ehrhardt FJ, Hsu D, Celenti RS, Grbic JT, et al. Gingival crevicular fluid levels of interleukin-1beta and glycemic control in patients with chronic periodontitis and type 2 diabetes. J Periodontol. 2004;75(9):1203-8

34. Kinane DF, Preshaw PM, Loos BG. Host-response: understanding the cellular and molecular mechanisms of host-microbial interactions-consensus of the Seventh European Workshop on Periodontology. J Clin Periodontol. 2011;38 Suppl 11:44-8.

35. Kishimoto T. Interleukin-6: discovery of a pleiotropic cytokine. Arthritis Res Ther. 2006;8 Suppl 2:S2

36. Hosokawa Y, Shindo S, Hosokawa I, Ozaki K, Matsuo T. IL-6 trans-signaling enhances CCL20 production from IL-1beta-stimulated human periodontal ligament cells. Inflammation. 2014;37(2):381-6.

37. Tilg H, Trehu E, Atkins MB, Dinarello CA, Mier JW. Interleukin-6 (IL-6) as an anti-inflammatory cytokine: induction of circulating $\mathrm{L}-1$ receptor antagonist and soluble tumor necrosis factor receptor p55. Blood. 1994;83(1):113-8.

38. Khosravi R, Ka K, Huang T, Khalili S, Nguyen BH, Nicolau B, et al. Tumor necrosis factor- alpha and interleukin-6: potential interorgan inflammatory mediators contributing to destructive periodontal disease in obesity or metabolic syndrome. Mediators Inflamm. 2013;2013:728987.

39. Javed F, Al-Askar M, Al-Hezaimi K. Cytokine profile in the gingival crevicular fluid of periodontitis patients with and without type 2 diabetes: a literature review. J Periodontol. 2012;83(2):156-61.

40. Ribeiro FV, de Mendonça AC, Santos VR, Bastos MF, Figueiredo LC, Duarte PM. Cytokines and bone-related factors in systemically healthy patients with chronic periodontitis and patients with type 2 diabetes and chronic periodontitis. J Periodontol. 2011;82(8):1187-96.

41. Chamberlain CS, Leiferman EM, Frisch KE, Wang S, Yang X, Brickson SL, et al. The influence of interleukin-4 on ligament healing. Wound Repair Regen. 2011;19(3):426-35.

42. Baggiolini M, Dewald B, Moser B. Human chemokines: an update. Annu Rev Immunol. 1997:15:675-705.

43. Longo PL, Artese HP, Rabelo MS, Kawamoto D, Foz AM, Romito GA, et al. Serum levels of inflammatory markers in type 2 diabetes patients with chronic periodontitis. J Appl Oral Sci. 2014;22(2):103-8.

44. Maurer M, von Stebut E. Macrophage inflammatory protein-1. Int J Biochem Cell Biol. 2004;36(10):1882-6.

45. Gemmell E, Carter CL, Seymour GJ. Chemokines in human periodontal disease tissues. Clin Exp Immunol. 2001;125(1):134-41.

46. Sonmez AB, Castelnuovo J. Applications of basic fibroblastic growth factor (FGF-2, bFGF) in dentistry. Dent Traumatol. 2014;30(2):107-11.

47. Barrientos S, Brem H, Stojadinovic O, Tomic-Canic M. Clinical application of growth factors and cytokines in wound healing. Wound Repair Regen. 2014;22(5):569-78.

48. Moriya J, Ferrara N. Inhibiting the response to VEGF in diabetes. Sci Signal. 2014;7(307):e1

49. Sakallioglu EE, Aliyev E, Lutfioglu M, Yavuz U, Acikgoz G. Vascular endothelial growth factor (VEGF) levels of gingiva and gingival crevicular fluid in diabetic and systemically healthy periodontitis patients. Clin Oral Investig. 2007;11(2):115-20.

50. Guneri P, Unlu F, Yesilbek B, Bayraktar F, Kokuludag A, Hekimgil M, et al. Vascular endothelial growth factor in gingival tissues and crevicular fluids of diabetic and healthy periodontal patients. J Periodontol. 2004;75(1):91-7.
51. Van Dyke TE, van Winkelhoff AJ. Infection and inflammatory mechanisms. J Clin Periodontol. 2013:40 Suppl 14:S1-7.

52. Goswami R, Kaplan MH. A brief history of IL-9. J Immunol. 2011;186(6):3283-8.

53. Van Dyke TE. Cellular and molecular susceptibility determinants for periodontitis. Periodontol 2000. 2007:45:10-3.

54. Garlet GP. Destructive and protective roles of cytokines in periodontitis: a re-appraisal from host defense and tissue destruction viewpoints. J Dent Res. 2010;89(12):1349-63.

55. Wu Y, Liu F, Zhang $X$, Shu L. Insulin modulates cytokines expression in human periodontal ligament cells. Arch Oral Biol. 2014;59(12):1301-6.

56. Preshaw PM, Foster N, Taylor JJ. Cross-susceptibility between periodontal disease and type 2 diabetes mellitus: an immunobiological perspective. Periodontol 2000. 2007:45:138-57.

57. Fernandez y Mostajo M, Zaura E, Crielaard W, Beertsen W. Does routine analysis of subgingival microbiota in periodontitis contribute to patient benefit? Eur J Oral Sci. 2011;119(4):259-64.

58. Kinney JS, Morelli T, Oh M, Braun TM, Ramseier CA, Sugai JV, et al. Crevicular fluid biomarkers and periodontal disease progression. J Clin Periodontol. 2014;41(2):113-20.

59. Petropoulos G, McKay IJ, Hughes FJ. The association between neutrophil numbers and interleukin-1alpha concentrations in gingival crevicular fluid of smokers and non-smokers with periodontal disease. J Clin Periodontol. 2004;31(5):390-5.

60. Burstyn I, Yang Y, Schnatter AR. Effects of non-differential exposure misclassification on false conclusions in hypothesis-generating studies. Int J Environ Res Public Health. 2014;11(10):10951-66.

61. Zhong Y, Slade GD, Beck JD, Offenbacher S. Gingival crevicular fluid interleukin-1beta, prostaglandin E2 and periodontal status in a community population. J Clin Periodontol. 2007;34(4):285-93.

62. Lopez R, Dahlen G, Baelum V. Subgingival microbial consortia and the clinical features of periodontitis in adolescents. European journal of oral sciences. 2011;119(6):455-62.

63. Zimmermann H, Hagenfeld D, Diercke K, El-Sayed N, Fricke J, Greiser KH, et al. Pocket depth and bleeding on probing and their associations with dental, lifestyle, socioeconomic and blood variables: a cross-sectional, multicenter feasibility study of the German National Cohort. BMC oral health. 2015;15:7.

\section{Submit your next manuscript to BioMed Central and take full advantage of:}

- Convenient online submission

- Thorough peer review

- No space constraints or color figure charges

- Immediate publication on acceptance

- Inclusion in PubMed, CAS, Scopus and Google Scholar

- Research which is freely available for redistribution 